\title{
Net mitigation potential of straw return to Chinese cropland: estimation with a full greenhouse gas budget model
}

\author{
Fei Lu, ${ }^{1,2}$ Xiaoke Wang, ${ }^{1,3}$ Bing Han, ${ }^{1}$ Zhiyun Ouyang,,${ }^{1}$ Xiaonan Duan, ${ }^{1}$ and Hua Zheng ${ }^{1}$ \\ ${ }^{1}$ State Key Laboratory of Urban and Regional Ecology, Research Center for Eco-Environmental Science, \\ Chinese Academy of Sciences, Beijing 100085 China \\ ${ }^{2}$ Graduate University of Chinese Academy of Sciences, Beijing 100049 China
}

\begin{abstract}
Based on the carbon-nitrogen cycles and greenhouse gas (GHG) mitigation and emission processes related to straw return and burning, a compound greenhouse gas budget model, the "Straw Return and Burning Model" (SRBM), was constructed to estimate the net mitigation potential of straw return to the soil in China. As a full GHG budget model, the SRBM addressed the following five processes: (1) soil carbon sequestration, (2) mitigation of synthetic $\mathrm{N}$ fertilizer substitution, (3) methane emission from rice paddies, (4) additional fossil fuel use for straw return, and (5) $\mathrm{CH}_{4}$ and $\mathrm{N}_{2} \mathrm{O}$ emissions from straw burning in the fields. Two comparable scenarios were created to reflect different degrees of implementation for straw return and straw burning. With GHG emissions and mitigation effects of the five processes converted into global warming potential (GWP), the net GHG mitigation was estimated. We concluded that (1) when the full greenhouse gas budget is considered, the net mitigation potential of straw return differs from that when soil carbon sequestration is considered alone; (2) implementation of straw return across a larger area of cropland in 10 provinces (i.e., Shanghai, Jiangsu, Zhejiang, Fujian, Jiangxi, Hubei, Hunan, Guangdong, Guangxi, and Hainan) will increase net GHG emission; (3) if straw return is promoted as a feasible mitigation measure in the remaining provinces, the total net mitigation potential before soil organic carbon (SOC) saturation will be $71.89 \mathrm{Tg} \mathrm{CO}_{2}$ equivalent (eqv)/yr, which is equivalent to $1.733 \%$ of the annual carbon emission from fossil fuel use in China in 2003; (4) after SOC saturation, only 13 of 21 provinces retain a relatively small but permanent net mitigation potential, while in the others the net GHG mitigation potential will gradually diminish; and (5) the major obstacle to the feasibility or permanence of straw return as a mitigation measure is the increased $\mathrm{CH}_{4}$ emission from rice paddies. The paper also suggests that comparable scenarios in which all the related carbon-nitrogen cycles are taken into account be created to estimate the mitigation potentials of organic wastes in different utilizations and treatments.
\end{abstract}

Key words: China; global warming potential; greenhouse gas; methane; mitigation; soil carbon sequestration; soil organic carbon; straw return.

\section{INTRODUCTION}

The input of organic detritus is a determining factor in the level of organic carbon in soil (SOC; Lal 2004a, Post et al. 2004). Straw return to the soil can directly increase the organic carbon input and therefore sequester carbon in cropland soil. In China, straw return is regarded as an effective method of soil carbon sequestration $(34.4 \mathrm{Tg} \mathrm{C} /$ yr; Lu et al. 2009) and a major factor in the increase in organic carbon in the surface soil of croplands over the past 20 years (Huang and Sun 2006). In recent years, the carbon sequestration rates and potentials for straw return have been estimated for developed countries and on a global scale. The results indicated that straw return is one of the most sustainable and economical carbon

Manuscript received 3 November 2008; revised 9 July 2009; accepted 10 July 2009; final version received 5 August 2009. Corresponding Editor: J. Gulledge.

${ }^{3}$ Corresponding author. E-mail: wangxk@rcees.ac.cn sequestration methods (Triberti et al. 2008) with great potential (Smith et al. 1997, Vleeshouwers and Verhagen 2002).

Greenhouse gases released from processes such as the manufacture and use of agricultural products may negate all or part of the increased $\mathrm{C}$ sequestered by soils (Schlesinger 2000, Smith et al. 2001, Chen et al. 2008, Lu et al. 2008). When a soil carbon sequestration measure affects more than one gas through multiple and sometimes opposing mechanisms, the net benefit depends upon the combined effects on all gases (IPCC 2007a) rather than the impact on the soil carbon pool alone (Smith 2004). Studies of full greenhouse gas (GHG) budgets and net mitigation potentials have been initiated for several soil carbon sequestration measures including conservation tillage (Smith et al. 2001, West and Marland 2002, Six et al. 2004), nitrogen fertilizer application in croplands (Schlesinger 2000, Lu et al. 2008), and water management in rice paddies ( $\mathrm{Li}$ et al. 2005b). The scenarios in these studies were paired, with 
one scenario describing the implementation of a particular sequestration measure and an opposing scenario in which no sequestration measure was adopted.

The net mitigation potential of straw return depends on the changes in the disposition of carbon and nitrogen. Millions of tons of straw are produced annually as an agricultural by-product. Regardless of whether the straw is returned to the croplands, the huge amounts of carbon and nitrogen in the straw do not vanish, but in one way or another remain part of the global carbon and nitrogen cycles. Because of this, scenarios in which no straw is returned that do not specify an alternate disposition are meaningless. This highlights the necessity of considering all straw in comparison studies, even the straw that is not returned to croplands. Different treatments will result in widely varying levels of GHG emission, and some treatments may demonstrate GHG mitigation potentials when compared against present practices. The necessity of comparison was described in a recent study, in which the soil carbon sequestration potential of straw return and the mitigation potential of straw combustion for electric power generation were compared (Powlson et al. 2008). However, there has been no overall quantitative analysis that integrates the effects of multiple gases emitted during various crop straw treatment processes or an analysis of the net mitigation potential of straw return compared with other straw utilization alternatives.

In the past decade, China produced $\sim 630 \times 10^{6} \mathrm{Mg}$ of crop straw per year (Liu et al. 2008). In order to reduce the time and expense of handling, many farmers burn straw in the fields. Although the Chinese government makes efforts to prohibit straw burning, it remains a common practice in China's countryside (Cao et al. 2007). Straw combustion to generate electric power faces a series of technical, economic, and managerial problems and risks (Cui 2007, Fu et al. 2007, Gu 2007), and straw return is regarded as the most effective measure to resolve the problem of burning. Considering the huge amount of straw produced and burned, it is important to estimate the net mitigation effect when the straw is instead returned to the soil.

The change from straw burning to straw return influences the carbon-nitrogen cycles and GHG emissions. Besides carbon sequestration in soil, straw return can eliminate non- $\mathrm{CO}_{2} \mathrm{GHG}$ (i.e., $\mathrm{CH}_{4}$ and $\mathrm{N}_{2} \mathrm{O}$ ) emissions from incomplete straw burning. Furthermore, the nitrogen in the straw returned can substitute for synthetic nitrogen fertilizer ( $\mathrm{Li}$ et al. 2003b), reducing the amount of fertilizer applied and mitigating $\mathrm{GHG}$ emissions from synthetic fertilizer production. However, straw return may also lead to an increase in some GHG emissions. Additional fossil fuel is required to return the straw in order to ensure the sowing and growth of the next crop (Liu et al. 2001, Chen et al. 2008). Straw return also stimulates $\mathrm{CH}_{4}$ emission from rice paddies and direct $\mathrm{N}_{2} \mathrm{O}$ emission (IPCC 2000). Therefore, the true contribution of straw return to the mitigation of global warming lies in the overall effect of the abovementioned processes.

It should be emphasized that $\mathrm{C}$ sequestration in soils does not represent a "permanent" solution of mitigation (Hutchinson et al. 2007). Once a new equilibrium is achieved, carbon can no longer be sequestered in the soil. On the other hand, some other agricultural mitigation effects are non-saturating, such as the reduction in $\mathrm{N}_{2} \mathrm{O}$ and $\mathrm{CH}_{4}$ emissions and the emissions avoided as a result of gains in agricultural energy efficiency (Smith et al. 2007). The effectiveness of straw return as a carbon mitigation measure after SOC saturation depends on the emission of other greenhouse gases and the mitigation potential derived from replacing synthetic fertilizers.

We examined the GHG emission or mitigation associated with straw return and burning in China. Our specific objectives were (1) to quantify each contributor to GHG emission, mitigation, and sequestration relevant to straw burning and return; (2) to estimate the manner in which GHG emissions and mitigation may change if straw return techniques are implemented at varying levels (i.e., different scenarios) in China; (3) to estimate the total effective GHG emissions of different scenarios and the net mitigation potential compared with the baseline scenario; (4) to extend the estimation of net mitigation potential after SOC saturation; and (5) to assess the feasibility and permanence of straw return as a mitigation measure in China. As the full GHG budget analysis of straw return and burning is complex, an integrated empirical model referred to as the "Straw Return and Burning Model" (SRBM) was constructed to provide quantitative answers to these questions.

\section{Methods \\ Structure of the SRBM}

The inputs to the SRBM are the proportions of cropland to which straw is returned $\left(\mathrm{PR}_{i}\right)$ or burned $\left(\mathrm{PB}_{i}\right)$ in province $i$. We assumed that the straw was either returned to cropland or burned, so the sum of $\mathrm{PR}_{i}$ and $\mathrm{PB}_{i}$ was $100 \%$.

Five processes were considered in order to estimate GHG emissions and sequestration/mitigation (Fig. 1). These included (1) soil carbon sequestration, resulting in the mitigation of soil carbon sequestration with straw return (expressed as MSCS, in teragrams of $\mathrm{CO}_{2}$ per year), (2) mitigation of synthetic $\mathrm{N}$ fertilizer substitution, with the result expressed as MNS (in teragrams of $\mathrm{CO}_{2}$ equivalent [eqv] per year) which is equivalent to the greenhouse effects emitted from synthetic fertilizer production, (3) methane emission from rice paddies, resulting in the global warming potential (GWP) of $\mathrm{CH}_{4}$ emitted from rice paddies (expressed as EP, in teragrams of $\mathrm{CO}_{2}$ equivalent per year), (4) additional fossil fuel use for straw return, resulting in the global warming potential of GHG emissions from the additional diesel oil 
Input/treatments

of straw

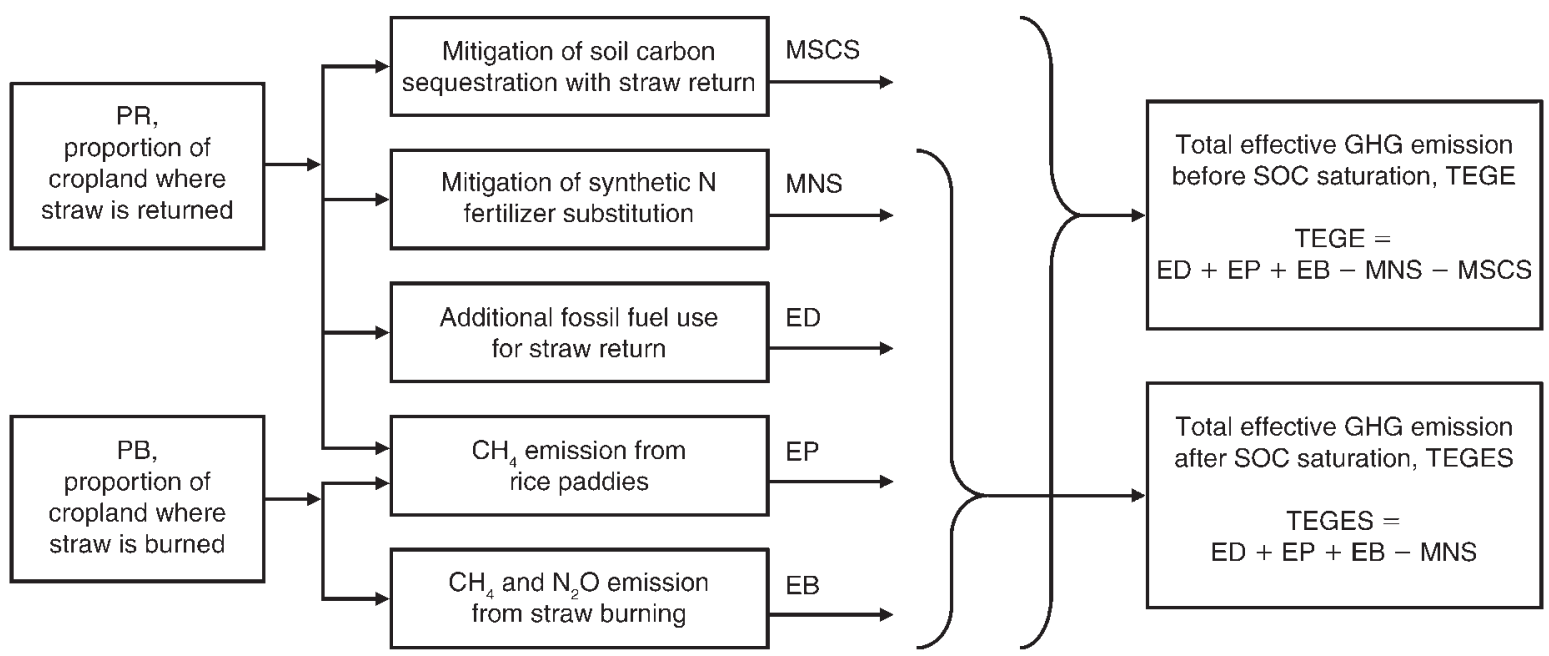

FIG. 1. Structure of the Straw Return and Burning Model (SRBM), constructed to estimate the net mitigation potential of straw return to the soil in China. Other abbreviations are: ED, global warming potential of greenhouse gas (GHG) emissions from the additional diesel oil consumption during tilling and plowing; SOC, soil organic carbon.

consumption during tilling and plowing (expressed as $\mathrm{ED}$, in teragrams of $\mathrm{CO}_{2}$ equivalent per year), and (5) $\mathrm{CH}_{4}$ and $\mathrm{N}_{2} \mathrm{O}$ emissions from straw burning in the fields, resulting in the total global warming potential of $\mathrm{CH}_{4}$ and $\mathrm{N}_{2} \mathrm{O}$ emissions from straw burning (expressed as $\mathrm{EB}$, in teragrams of $\mathrm{CO}_{2}$ equivalent per year). With the input of the proportion of the cropland on which straw return was implemented, the model integrated the effects of the five processes (i.e., MSCS, MNS, EP, ED, and EB) with the global warming potential of each of the gases (IPCC $2007 b$ ) and calculated the total effective GHG emissions before (TEGE) and after (TEGES) soil organic carbon saturation in province $i$ using the following equations:

$$
\begin{aligned}
\mathrm{TEGE}_{i} & =\mathrm{EB}_{i}+\mathrm{ED}_{i}+\mathrm{EP}_{i}-\left(\mathrm{MSCS}_{i}+\mathrm{MNS}_{i}\right) \\
\mathrm{TEGES}_{i} & =\mathrm{EB}_{i}+\mathrm{ED}_{i}+\mathrm{EP}_{i}-\mathrm{MNS}_{i} .
\end{aligned}
$$

Eqs. 3 and 4 were used to compare the net mitigation potentials of each scenario with the baseline both before $\left(\mathrm{NMP}_{i}\right)$ and after SOC saturation $\left(\mathrm{NMPS}_{i}\right)$ :

$$
\begin{aligned}
\mathrm{NMP}_{i} & =\mathrm{TEGE}_{\mathrm{b} i}-\mathrm{TEGE}_{\mathrm{p} i} \\
\mathrm{NMPS}_{i} & =\mathrm{TEGES}_{\mathrm{b} i}-\mathrm{TEGES}_{\mathrm{p} i} .
\end{aligned}
$$

The variables $\mathrm{TEGE}_{\mathrm{b} i}$ and $\mathrm{TEGE}_{\mathrm{p} i}$ are the total effective GHG emissions of the baseline and predictive scenarios before SOC saturation, while TEGES $_{\mathrm{b} i}$ and $\mathrm{TEGES}_{\mathrm{p} i}$ are the total effective GHG emissions of the baseline and predictive scenarios after SOC saturation.

\section{Processes within the SRBM}

Soil carbon sequestration.-The mitigation of soil carbon sequestration (MSCS) was calculated by multiplying the soil carbon sequestration rate by the area in which straw return techniques were implemented at the provincial level, and the total for the entire country was determined using the following equation:

$$
\mathrm{MSCS}=\sum\left(\mathrm{SCSR}_{i} \times A_{i} \times \mathrm{PR}_{i}\right) \times 10^{-9} \times 44 / 12 .
$$

The $\mathrm{SCSR}_{i}$ term is the soil carbon sequestration rate in kilograms of $\mathrm{C}$ per hectare per year, $\mathrm{PR}_{i}$ is the proportion of the cropland on which straw is returned, and $A_{i}$ (in hectares) is the area of the cropland where straw return could potentially be implemented in province $i$ (see Appendix A). The values of $A_{i}$ and $\mathrm{PR}_{i}$ are listed in Table 1.

The relationship between $\operatorname{SCSR}_{i}$ and the amount of straw returned was determined from 117 pairs of published long-term experimental data (see Appendices D and G) and is expressed in Eqs. 6-9.

For Beijing, Tianjin, Hebei, Shanxi, Inner Mongolia, Henan, and Shandong provinces,

$$
\begin{aligned}
\operatorname{SCSR}_{i}= & 0.0406 \times S_{i}+181.89 \\
& \left(n=33, R^{2}=0.185, P=0.013\right) .
\end{aligned}
$$

For Heilongjiang, Jilin, and Liaoning provinces,

$$
\begin{array}{rl}
\operatorname{SCSR}_{i}=0 & 0.045 \times S_{i}+340.33 \\
& \left(n=27, R^{2}=0.490, P<0.001\right) .
\end{array}
$$

For Jiangsu, Anhui, Shanghai, Zhejiang, Fujian, Hubei, Hunan, Guangdong, Guangxi, Chongqing, Sichuan, Guizhou, Yunnan, and Tibet,

$$
\begin{aligned}
\operatorname{SCSR}_{i}= & 0.0435 \times S_{i}+375.1 \\
& \left(n=33, R^{2}=0.184, P<0.013\right) .
\end{aligned}
$$


TABLE 1. Description of scenarios for provinces of China.

\begin{tabular}{|c|c|c|c|c|c|}
\hline Province & $A_{i}\left(10^{3}\right.$ ha $)$ & $\mathrm{ST}_{i}\left(10^{6} \mathrm{Mg}\right)$ & $S_{i}\left(\mathrm{~kg} \cdot \mathrm{ha}^{-1} \cdot \mathrm{yr}^{-1}\right)$ & Baseline $\mathrm{PR}_{i}(\%)$ & $\overline{\mathrm{DOA}_{i}(\mathrm{Mg} / \mathrm{ha})}$ \\
\hline Beijing & 130.3 & 0.914 & 7018 & 47.3 & 2.810 \\
\hline Tianjin & 295.4 & 2.200 & 7447 & 47.3 & 3.017 \\
\hline Hebei & 4473.6 & 37.684 & 8424 & 47.3 & 3.413 \\
\hline Shanxi & 2825.4 & 14.340 & 5075 & 55.7 & 2.041 \\
\hline Inner Mongolia & 4566.1 & 22.075 & 4834 & 15 & 1.920 \\
\hline Liaoning & 2497.7 & 21.346 & 8546 & 31.1 & 3.771 \\
\hline Jilin & 4095.0 & 35.576 & 8688 & 15 & 3.160 \\
\hline Heilongjiang & 5248.2 & 23.830 & 4540 & 35.1 & 3.507 \\
\hline Shanghai & 131.1 & 0.820 & 6251 & 47.8 & 2.639 \\
\hline Jiangsu & 3277.3 & 24.963 & 7617 & 31.9 & 3.195 \\
\hline Zhejiang & 1026.6 & 5.762 & 5612 & 23.9 & 2.369 \\
\hline Anhui & 3950.7 & 23.917 & 6054 & 30.3 & 2.527 \\
\hline Fujian & 643.0 & 3.883 & 6039 & 35.5 & 2.552 \\
\hline Jiangxi & 1943.4 & 9.849 & 5068 & 65.1 & 2.151 \\
\hline Shandong & 4624.0 & 52.876 & 11435 & 23.6 & 4.647 \\
\hline Henan & 5349.0 & 50.744 & 9487 & 34.6 & 3.932 \\
\hline Hubei & 3143.1 & 19.257 & 6127 & 38 & 2.567 \\
\hline Hunan & 2447.5 & 18.600 & 7600 & 20 & 3.193 \\
\hline Guangdong & 1660.4 & 9.721 & 5855 & 41.4 & 2.459 \\
\hline Guangxi & 2579.1 & 15.816 & 6132 & 15 & 2.544 \\
\hline Hainan & 363.2 & 1.430 & 3938 & 38 & 1.651 \\
\hline Chongqing & 1465.8 & 9.450 & 6447 & 15 & 2.642 \\
\hline Sichuan & 4114.6 & 29.543 & 7180 & 14.3 & 2.964 \\
\hline Guizhou & 3066.8 & 12.399 & 4043 & 15 & 1.645 \\
\hline Yunnan & 3938.2 & 16.584 & 4211 & 15 & 1.714 \\
\hline Tibet & 106.1 & 0.507 & 4778 & 15 & 2.020 \\
\hline Shaanxi & 3608.0 & 14.419 & 3996 & 32 & 2.907 \\
\hline Gansu & 3050.6 & 10.261 & 3364 & 26.8 & 4.029 \\
\hline Qinghai & 474.4 & 1.158 & 2440 & 15 & \\
\hline Ningxia & 747.1 & 3.898 & 5217 & 7 & 4.256 \\
\hline Xinjiang & 2774.3 & 17.118 & 6170 & 15 & 4.053 \\
\hline Total & 78616.3 & 510.941 & & & \\
\hline
\end{tabular}

Notes: Provinces include municipalities and autonomous regions. Abbreviations are: $A_{i}$, cropland area in province $i ; \mathrm{ST}_{i}$, total amount of straw that can be returned to the soil; $S_{i}$, amount of straw returned to cropland; $\mathrm{PR}_{i}$, proportion of cropland where straw is returned; $\mathrm{DOA}_{i}$, amount of seasonal dry matter of non-fermented organic matter returned. Data of Special Administrative Region (SAR) of Hong Kong, SAR of Macao, and Taiwan Province are not included.

For Shaanxi, Gansu, Ningxia, Qinghai, and Xinjiang,

$$
\begin{array}{rl}
\operatorname{SCSR}_{i}=0 & 0171 \times S_{i}+30.553 \\
& \left(n=24, R^{2}=0.392, P<0.001\right) .
\end{array}
$$

In Eqs. 6-9, $S_{i}$ is the amount of straw returned per unit area of cropland (in kilograms of straw per hectare per year). This value, as well as the total amount of straw that can be returned to cropland in province $i\left(\mathrm{ST}_{i}\right)$, are obtained using Eqs. 10 and 11 (and are listed in Table 1):

$$
\begin{aligned}
\mathrm{ST}_{i} & =\sum \mathrm{CY}_{i j} \times \mathrm{SGR}_{j} \\
\mathrm{~S}_{i} & =\mathrm{ST}_{i} / A_{i}
\end{aligned}
$$

where $\mathrm{CY}_{i j}$ is the yield of crop $j$ in province $i$, obtained from the China Agriculture Yearbook (Editorial Board of China Agriculture Yearbook 2005) and $\mathrm{SGR}_{j}$ is the straw: grain ratio for crop $j$, adopted from the Assessment of Biomass Resource Availability in China (MOA/DOE Project Expert Team 1998) (Table 2).

Mitigation of synthetic $N$ fertilizer substitution.-A number of field experiments on straw return and soil nutrients have demonstrated that the nitrogen in straw can substitute for at least the same amount of synthetic
$\mathrm{N}$ in terms of yields (Zhang 1998, Zhang et al. 1999, Wang et al. 2005) as well as several soil $\mathrm{N}$ indices, such as total N (Niu et al. 1998, Zhang 1998, Gao et al. 2000 b, Sun et al. 2003, Peng et al. 2004, Wang et al. 2005), available N (Niu et al. 1998, Zhang et al. 1999, Wang et al. 2005), and alkalized N (Niu et al. 1998, Zhang et al. 1999). Yan et al. (2004) also reported that straw return is better than synthetic nitrogen fertilizer application for increasing total $\mathrm{N}$, available $\mathrm{N}$, miner-

TABLE 2. Straw: grain ratios (SGR), nitrogen and carbon fractions, and dry matter fractions (DMF) for straw.

\begin{tabular}{llccr}
\hline \hline \multicolumn{1}{c}{ Crop } & SGR & N fraction (\%) & C fraction (\%) & DMF \\
\hline Paddy rice & 0.623 & 0.91 & 41.8 & 0.85 \\
Wheat & 1.366 & 0.65 & 39.9 & 0.85 \\
Corn & 2 & 0.92 & 44.4 & 0.78 \\
Sorghum & 1 & 1.25 & 49.9 & 0.91 \\
Potato & 0.5 & 2.65 & 42.26 & 0.85 \\
Rapeseed & 2 & 0.87 & 44.9 & 0.85 \\
Sunflower & 2 & 0.82 & 40 & 0.85 \\
Cotton & 3 & 1.24 & 45 & 0.85 \\
Sugarcane & 0.1 & 1.10 & 45.7 & 0.83 \\
\hline
\end{tabular}

Note: The "Straw Return and Burning Model" (SRBM), a compound greenhouse gas budget model, was constructed to estimate the net mitigation potential of straw return to the soil in China. 
TABLE 3. Methane emission factors from rice paddies.

\begin{tabular}{lcc}
\hline \hline \multicolumn{1}{c}{ Type of paddy rice, by province } & Emission factors $(\mathrm{kg} \mathrm{CH} / \mathrm{ha})^{\mathrm{S}}$ & $n$ \\
\hline Helongiang, Jilin, Liaoning, Shaanxi, Gansu, Ningxia, Xinjiang & & 131 \\
$\quad$ Semi-late rice or single-cropping late rice & & 1 \\
Beijing, Tianjin, Hebei, Shanxi, Inner Mongolia, Henan, Shandong & 279.4 & 17 \\
$\quad$ Semi-late rice or single-cropping late rice & & 226.1 \\
Jiangsu, Anhui, Shanghai, Zhejiang, Jiangxi, Fujian, Hubei, & & 177.5 \\
Hunan, Guangdong, Guangxi, Hainan, Chongqing, Sichuan, & 193.5 & 22 \\
Guizhou, Yunnan and Tibet & 300.0 & 47 \\
Early rice & & 178.8 \\
Semi-late rice or single-cropping late rice & & 297.7 \\
Double-cropping late rice & & 45 \\
\hline
\end{tabular}

Notes: Provinces include municipalities and autonomous regions. Data of Special Administrative Region (SAR) of Hong Kong, SAR of Macao, and Taiwan Province are not included. No paddy rice was planted in Qinghai Province in 2003.

alizable $\mathrm{N}$, total hydrolyzed $\mathrm{N}$, amino $\mathrm{N}$, amino-sugar $\mathrm{N}$, and hydrolyzable N. Furthermore, returning straw to croplands can reduce the ammonia volatilization loss (Dong et al. 2005) and the loss of dissolved $\mathrm{N}$ through leaching (Ma et al. 2003), raising the efficiency of the fertilizer application. In our models it was conservatively estimated that the nitrogen in straw could substitute for at least the same amount of synthetic N.

The mitigation of synthetic $\mathrm{N}$ fertilizer substitution (MNS) can be obtained from the following equation:

$$
\mathrm{MNS}_{i}=\sum \mathrm{CY}_{i j} \times \mathrm{SGR}_{j} \times \mathrm{FN}_{j} \times \mathrm{DMF}_{j} \times \mathrm{PR}_{i} \times \mathrm{EFSNF}
$$

where $\mathrm{MNS}_{i}$ is the mitigation of synthetic $\mathrm{N}$ fertilizer substitution (in teragrams of $\mathrm{CO}_{2}$-eqv per year), and $\mathrm{FN}_{j}$ and $\mathrm{DMF}_{j}$ represent the $\mathrm{N}$ fraction and dry matter fraction for the straw of crop $j$. These values were derived from "The Organic Fertilizer of China" (The National Center for Services and Popularization of Agricultural Techniques 1999), IPCC (1997, 2000), Wang (1999), and Dai et al. (2000) (Table 2). In Eq. 12, EFSNF is the emission factor of the GHG from synthetic $\mathrm{N}$ fertilizer production; the value was set at 6.408 $\mathrm{Mg} \mathrm{CO}$-eqv $/ \mathrm{Mg} \mathrm{N}$ in $\mathrm{CO}_{2}$ equivalent units (or $1.748 \mathrm{Mg} \mathrm{C}$-eqv/Mg $\mathrm{N}$ in carbon equivalent units; see Appendix B).

Methane emission from rice paddies.-The global warming potential of $\mathrm{CH}_{4}$ emitted from rice paddies (EP) was estimated using the methods recommended by IPCC (1997, 2000):

$$
\begin{aligned}
\mathrm{EP}= & {\left[\sum\left(\mathrm{EFM}_{i k} \times \mathrm{ASR}_{i k} \times \mathrm{PB}_{i} \times 10^{-9}\right)\right.} \\
& \left.+\sum\left(\mathrm{EFM}_{i k} \times \mathrm{SFo}_{i} \times \mathrm{ASR}_{i k} \times \mathrm{PR}_{i} \times 10^{-9}\right)\right] \times 25
\end{aligned}
$$

where $\mathrm{EFM}_{i k}$ is the seasonal emission factor of methane with no organic amendments for rice type $k$ production in province $i$, in kilograms of $\mathrm{CH}_{4}$ per hectare. The rice type $k$ may be early rice, double-cropping late rice, semilate rice, or single-cropping late rice. In Eq. $13, \mathrm{SFo}_{i}$ is the scaling factor after straw return in province $i$, and $\mathrm{ASR}_{i k}$ is the annual sown area in hectares per year of rice type $k$ in province $i$.

As synthetic $\mathrm{N}$ fertilization was widely implemented in China's rice paddies, a collection of 132 measurements of $\mathrm{CH}_{4}$ emission from rice paddies using only synthetic fertilizer (i.e., no organic amendments) was compiled (see Appendices E and G). We arranged the 30 provinces in which paddy rice was planted (no paddy rice was planted in Qinghai Province) into three groups in consideration of the rice cropping system and the distribution of the experimental sites. The $\mathrm{EFM}_{i k}$ for each type of paddy rice practice in each group was estimated (Table 3).

The scaling factor after straw return (SFo) depended on the amount of dry matter in the returned straw. In accordance with data obtained from field experiments in China (see Appendix F), the relationship between the amount of non-fermented organic amendments for each crop (in megagrams per hectare) and SFo was established based on the following equation:

$$
\begin{array}{rl}
\mathrm{SFo}_{i}=0 & .5757 \times \mathrm{DOA}_{i}+0.6521 \\
& \left(n=10, R^{2}=0.7513, P=0.001\right)
\end{array}
$$

where $\mathrm{DOA}_{i}$ is the seasonal amount of straw dry matter returned to each hectare of rice paddy in province $i$, in megagrams per hectare. The values of $\mathrm{DOA}_{i}$ are listed in Table 1, and the calculation process is described in Appendix C.

Additional fossil fuel use for straw return.-Due to the high multi-crop index in China, additional tilling or plowing is always required after straw return to ensure soil quality for the next crop. The global warming potential of GHG emissions from the additional diesel oil consumption during tilling and plowing $\left(\mathrm{ED}_{i}\right)$ was obtained using the following equation:

$$
\mathrm{ED}_{i}=\sum \mathrm{IEFD} \times \mathrm{PR}_{i} \times \mathrm{AS}_{i j} \times \mathrm{DU}_{i j} \times 10^{-6}
$$

where IEFD is the integrated GHG emission factor for diesel oil combustion, assigned as $3.172 \mathrm{Mg} \mathrm{CO}_{2}$-eqv/ 
$\mathrm{Mg}$ diesel oil (see Appendix B), $\mathrm{AS}_{i j}$ is the sown area of crop $j$ in province $i$ in hectares per year, cited from the China Agriculture Yearbook (Editorial Board of China Agriculture Yearbook 2005), and $\mathrm{DU}_{i j}$ is the diesel oil consumption in kilograms per hectare required to return the straw of crop $j$ for each hectare of cropland in province $i$, obtained from Chen et al. (2008).

Methane and $\mathrm{N}_{2} \mathrm{O}$ emissions from straw burning in the fields.-In order to compare the carbon-nitrogen cycles in straw burning and straw return, it was assumed that all the $\mathrm{C}$ and $\mathrm{N}$ in the straw would be emitted during burning. The total global warming potential of $\mathrm{CH}_{4}$ and $\mathrm{N}_{2} \mathrm{O}$ emissions from straw burning $\left(\mathrm{EB}_{i}\right.$, in teragrams of $\mathrm{CO}_{2}$ equivalent per year) was estimated using the emission factors and method recommended by IPCC (1997):

$$
\begin{aligned}
\mathrm{EB}_{i}= & 0.005 \times \mathrm{CB}_{i} \times 16 / 12 \times 25 \\
& +0.007 \times \mathrm{NB}_{i} \times 44 / 28 \times 298
\end{aligned}
$$

where $\mathrm{CB}_{i}$ and $\mathrm{NB}_{i}$ are the amounts of carbon and nitrogen in the burned straw (in teragrams per year). They were obtained using the following equations:

$$
\begin{aligned}
& \mathrm{NB}_{i}=\sum \mathrm{CY}_{i j} \times \mathrm{SGR}_{j} \times \mathrm{FN}_{j} \times \mathrm{DMF}_{j} \times \mathrm{PB}_{i} \\
& \mathrm{CB}_{i}=\sum \mathrm{CY}_{i j} \times \mathrm{SGR}_{j} \times \mathrm{FC}_{j} \times \mathrm{DMF}_{j} \times \mathrm{PB}_{i}
\end{aligned}
$$

where $\mathrm{FN}_{j}$ and $\mathrm{FC}_{j}$ are the $\mathrm{N}$ and $\mathrm{C}$ fractions for the straw of crop $j$ (Table 2). These values were derived from "The Organic Fertilizer of China" (The National Center for Services and Popularization of Agricultural Techniques 1999), IPCC (1997, 2000), Wang (1999), and Dai et al. (2000) (Table 2).

\section{Scenarios}

We constructed two scenarios for this study: (1) a baseline scenario reflecting the current status of straw return, and (2) FI, representing "full implementation of straw return." The settings of these scenarios focused on burning or return of the straw. In order to predict the net mitigation potential brought about by the change from straw burning to straw return, straw that was not returned to croplands was assumed to be burned in the field. In these two scenarios, the only difference lay in the treatment of the straw. Other factors such as total nitrogen fertilizer applied to croplands were set identically or kept steady in both scenarios.

Baseline scenario.-In the baseline scenario, straw return was implemented over a smaller area of cropland. The $\mathrm{PR}_{i}$ values for provinces in China varied from $7 \%$ to 67.1\% (Gao et al. 2000a, Li 2003, Yang et al. 2003, Zhong et al. 2003, Weng et al. 2004, Han et al. 2005; see Table 1). The total amount of straw returned to croplands was $1.442 \times 10^{8} \mathrm{Mg}$. According to the assumptions of the model, the remainder of the straw (amounting to $3.668 \times 10^{8} \mathrm{Mg}$ ) was assumed to be burned.
Full implementation scenario.-In the FI scenario, it was assumed that straw return techniques were fully implemented on all croplands in China and $\mathrm{PR}_{i}$ was $100 \%$ for every province. In this scenario, straw from rice, wheat, maize, sorghum, potato, rapeseed, sunflower, and cotton as well as sugarcane leaves were returned to croplands. The total amount of straw returned was $5.109 \times 10^{8} \mathrm{Mg}$, and no straw was burned (Table 1).

\section{RESUlts}

\section{Greenhouse gas emission factors and sequestration mitigation rates}

Implementation of straw return will sequester between 72.28 and $706.4 \mathrm{~kg} \mathrm{C} \cdot \mathrm{ha}^{-1} \cdot \mathrm{yr}^{-1}$, depending on the province, resulting in an annual mitigation effect of 265.0-2590 kg CO 2 -eqv $\cdot \mathrm{ha}^{-1} \cdot \mathrm{yr}^{-1}$ and a national mean of $1928 \mathrm{~kg} \mathrm{CO}$-eqv $\cdot \mathrm{ha}^{-1} \cdot \mathrm{yr}^{-1}$. In the rice paddies, the national average seasonal $\mathrm{CH}_{4}$ emission without straw return is $210.8 \mathrm{~kg} \mathrm{CH}_{4} / \mathrm{ha}$, and the GWP is $5270 \mathrm{~kg}$ $\mathrm{CO}_{2}$-eqv $\cdot \mathrm{ha}^{-1} \cdot \mathrm{yr}^{-1}$. With straw return, the mean GWP will rise to $11603 \mathrm{~kg} \mathrm{CO}$-eqv $\cdot \mathrm{ha}^{-1} \cdot \mathrm{yr}^{-1}$. On a national scale, the mean mitigation factor of synthetic nitrogen substitution is $302.9 \mathrm{~kg} \mathrm{CO}$-eqv $\cdot \mathrm{ha}^{-1} \cdot \mathrm{yr}^{-1}$, varying by location from 131.8 to $490.1 \mathrm{~kg} \mathrm{CO}_{2}$-eqv $\cdot \mathrm{ha}^{-1} \cdot \mathrm{yr}^{-1}$, depending on the amount and species of straw. Burning straw produces $\mathrm{N}_{2} \mathrm{O}$ and $\mathrm{CH}_{4}$ emissions. The global warming potential of non- $\mathrm{CO}_{2}$ GHGs varies from 214.0 to $909.1 \mathrm{~kg} \mathrm{CO}$-eqv $\cdot \mathrm{ha}^{-1} \cdot \mathrm{yr}^{-1}$. Returning the straw to croplands eliminates this type of GHG emission. The mean GHG emission resulting from the additional fossil fuel use is $67.54 \mathrm{~kg} \mathrm{CO}$-eqv $\cdot \mathrm{ha}^{-1} \cdot \mathrm{yr}^{-1}$. Due to differences in crop systems and species, the value of this factor varies by province from 23.15 to $118.1 \mathrm{~kg} \mathrm{CO}_{2}$-eqv. $\mathrm{ha}^{-1} \cdot \mathrm{yr}^{-1}$.

The net mitigation factor is an integration of the factors reported here. Before SOC saturation, the net mitigation factor of straw return was positive in 21 of the 31 provinces on the Chinese mainland (Table 4 ). The highest value was $2532 \mathrm{~kg} \mathrm{CO} 2$-eqv $\cdot \mathrm{ha}^{-1} \cdot \mathrm{yr}^{-1}$ in Jilin Province (Table 4). The net mitigation resulting from straw return was negative in Shanghai, Jiangsu, Zhejiang, Fujian, Jiangxi, Hubei, Hunan, Guangdong, Guangxi, and Hainan provinces (Table 4), meaning that in these 10 provinces, implementation of straw return in larger cropland areas would lead to an increase in net GHG emission. After SOC saturation, the net mitigation factors remained positive in only 13 provinces. The highest value was $711.1 \mathrm{~kg} \mathrm{CO} \mathrm{CO}_{2}$-eqv $\cdot \mathrm{ha}^{-1} \cdot \mathrm{yr}^{-1}$ in Shandong Province (Table 4).

\section{Baseline}

The TEGE of the baseline scenario is $171.7 \mathrm{Tg} \mathrm{CO}_{2}-$ eqv/yr before SOC saturation and 214.2 $\mathrm{Tg} \mathrm{CO}_{2}$-eqv/yr after SOC saturation (Table 5). The national total and provincial values of the sequestration, mitigation, and GHG emissions are shown in Table 5 and Figs. 2 and 3, respectively. 
TABLE 4. Net mitigation factors and potentials.

\begin{tabular}{|c|c|c|c|c|}
\hline \multirow[b]{2}{*}{ Province } & \multicolumn{2}{|c|}{ Net mitigation factors $\left(\mathrm{kg} \mathrm{CO}_{2}\right.$-eqv $\left.\cdot \mathrm{ha}^{-1} \cdot \mathrm{yr}^{-1}\right)$} & \multicolumn{2}{|c|}{ Net mitigation potentials $\left(\mathrm{Tg} \mathrm{CO}_{2}\right.$-eqv/yr) } \\
\hline & Before SOC saturation & After SOC saturation & Before SOC saturation & After SOC saturation \\
\hline Beijing & 1263.6 & 361.5 & 0.165 & 0.047 \\
\hline Tianjin & 1286.1 & 350.4 & 0.380 & 0.104 \\
\hline Hebei & 1419.7 & 407.3 & 6.351 & 1.822 \\
\hline Shanxi & 892.3 & 262.2 & 2.521 & 0.741 \\
\hline Inner Mongolia & 1611.6 & 433.0 & 7.359 & 1.977 \\
\hline Liaoning & 1646.0 & -88.2 & 4.111 & -0.220 \\
\hline Jilin & 2532.4 & 375.1 & 10.370 & 1.536 \\
\hline Heilongjiang & 735.2 & -512.2 & 3.859 & -2.688 \\
\hline Shanghai & -855.3 & -2093.7 & -0.112 & -0.274 \\
\hline Jiangsu & -411.5 & -2175.4 & -1.349 & -7.130 \\
\hline Zhejiang & -1649.5 & -3377.4 & -1.693 & -3.467 \\
\hline Anhui & 119.1 & -1512.5 & 0.471 & -5.975 \\
\hline Fujian & -3919.6 & -5427.9 & -2.520 & -3.490 \\
\hline Jiangxi & -1518.2 & -2280.3 & -2.950 & -4.432 \\
\hline Shandong & 2521.2 & 711.1 & 11.658 & 3.288 \\
\hline Henan & 1222.5 & -137.2 & 6.539 & -0.734 \\
\hline Hubei & -226.6 & -1685.3 & -0.712 & -5.297 \\
\hline Hunan & -6827.5 & -8897.5 & -16.710 & -21.776 \\
\hline Guangdong & -3073.3 & -4426.5 & -5.103 & -7.350 \\
\hline Guangxi & -2464.2 & -4464.6 & -6.356 & -11.515 \\
\hline Hainan & -603.0 & -1845.2 & -0.219 & -0.670 \\
\hline Chongqing & 222.3 & -1820.8 & 0.326 & -2.669 \\
\hline Sichuan & 85.0 & -2075.2 & 0.350 & -8.539 \\
\hline Guizhou & 1551.3 & -165.9 & 4.758 & -0.509 \\
\hline Yunnan & 1473.6 & -266.4 & 5.803 & -1.049 \\
\hline Tibet & 2225.8 & 409.0 & 0.236 & 0.043 \\
\hline Shaanxi & 454.0 & 207.5 & 1.638 & 0.749 \\
\hline Gansu & 541.4 & 305.0 & 1.652 & 0.930 \\
\hline Qinghai & 497.2 & 271.9 & 0.236 & 0.129 \\
\hline Ningxia & 601.9 & 193.5 & 0.450 & 0.145 \\
\hline Xinjiang & 963.2 & 539.2 & 2.672 & 1.496 \\
\hline Total $\uparrow$ & $\ldots$ & $\ldots$ & 34.18 & -74.78 \\
\hline
\end{tabular}

Notes: Provinces include municipalities and autonomous regions. Data of Special Administrative Region (SAR) of Hong Kong, SAR of Macao, and Taiwan Province are not included. The abbreviation "eqv" stands for "equivalent."

$\uparrow$ According to the results and conclusions of this paper, not all the provinces in China are suitable for the implementation of straw return as a mitigation measure. As a result, the national average values of the mitigation factors (before and after SOC saturation) do not have any scientific or realistic meaning and are represented by ellipses.

\section{The FI scenario}

In the FI scenario, straw return techniques are fully implemented and no straw is burned. The TEGE in the FI scenario is $137.4 \mathrm{Tg} \mathrm{CO}_{2}$-eqv/yr before SOC saturation. The national total and provincial values of the sequestration, mitigation, and GHG emissions are shown in Table 5 and Figs. 2 and 3, respectively.

When straw return is implemented over larger areas of cropland, soil carbon sequestration can increase by 29.72 Tg C/yr before SOC saturation occurs, which

TABLE 5. National total emissions, mitigation, and sequestration of each process ( $\mathrm{Tg} \mathrm{CO}_{2}$ equivalent/yr) at baseline and according to scenario FI, full implementation of straw return to the soil.

\begin{tabular}{lccccc}
\hline \hline & \multicolumn{2}{c}{ Baseline } & & \multicolumn{2}{c}{ FI } \\
\cline { 2 - 3 } Process & Before SOC saturation & After SOC saturation & & Before SOC saturation & After SOC saturation \\
\hline MSCS & 42.57 & 0 & 6.650 & 151.5 & 0 \\
MNS & 6.650 & 30.20 & 23.81 & 0 & 23.81 \\
EB & 30.20 & 1.503 & 189.2 & 5.214 & 0 \\
ED & 1.503 & 214.2 & & 307.5 & 5.214 \\
EP & 189.2 & & 37.4 & 307.5 \\
TEGE & 171.7 & & & 289.0 \\
NMP & & & & -74.70 \\
NMPS & & & & \\
\hline
\end{tabular}

Notes: Abbreviations are: MSCS, mitigation of soil carbon sequestration with straw return; MNS, mitigation of synthetic N fertilizer substitution; $\mathrm{EB}$, total global warming potential of $\mathrm{CH}_{4}$ and $\mathrm{N}_{2} \mathrm{O}$ emissions from straw burning; ED, global warming potential of greenhouse gas $(\mathrm{GHG})$ emissions from the additional diesel oil consumption during tilling and plowing; EP, global warming potential of $\mathrm{CH}_{4}$ emitted from rice paddies; TEGE, total effective GHG emissions before soil organic carbon (SOC) saturation; NMP, net mitigation potential before SOC saturation; NMPS, net mitigation potential after SOC saturation. EB, EP, and ED are expressed as positive values, while MSCS and MNS are expressed as negative values. Data of the Special Administrative Region (SAR) of Hong Kong, SAR of Macao, and Taiwan Province are not included. 


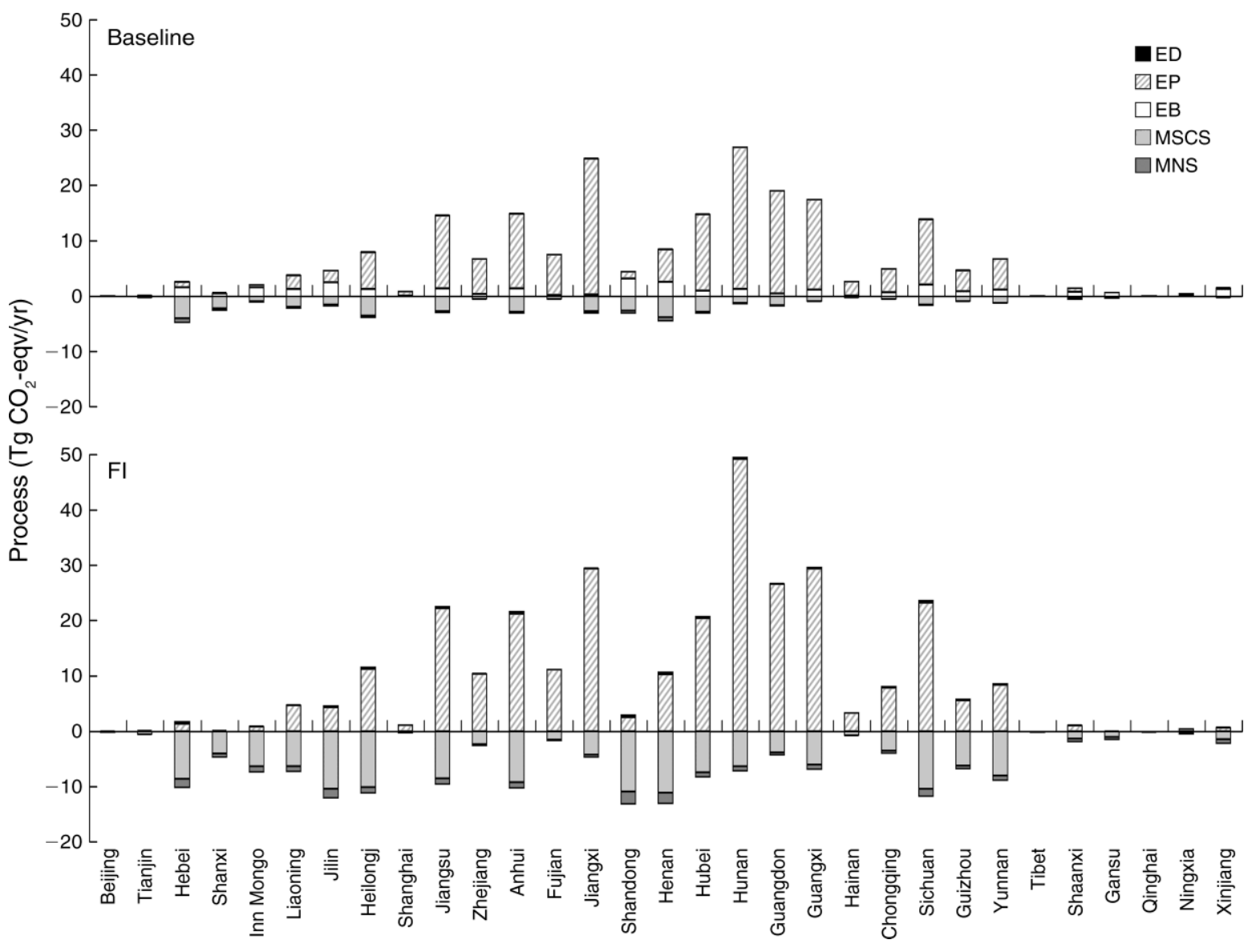

FIG. 2. Emissions, mitigation, and sequestration of each process before soil organic carbon (SOC) saturation, by Chinese province, at baseline and according to scenario FI, full implementation of straw return to the soil. Abbreviations are: EB, total global warming potential of $\mathrm{CH}_{4}$ and $\mathrm{N}_{2} \mathrm{O}$ emissions from straw burning; EP, global warming potential of $\mathrm{CH}_{4}$ emitted from rice paddies; ED, global warming potential of greenhouse gas $(\mathrm{GHG})$ emissions from the additional diesel oil consumption during tilling and plowing; MSCS, mitigation of soil carbon sequestration with straw return; MNS, mitigation of synthetic N fertilizer substitution. EB, EP, and ED are expressed as positive values, while MSCS and MNS are expressed as negative values. Inner Mongolia is abbreviated as "Inn Mongo"; Heilongjiang is abbreviated as "Heilongj"; Guangdong is abbreviated as "Guangdon." Data of Special Administrative Region (SAR) of Hong Kong, SAR of Macao, and Taiwan Province are not included.

indicates a mitigation potential in soil of $109.0 \mathrm{Tg} \mathrm{CO}_{2}^{-}$ eqv/yr through greater implementation of straw return techniques. When the entire budget of GHG emissions is considered, the national NMP is only $34.26 \mathrm{Tg} \mathrm{CO}_{2}$-eqv/ $\mathrm{yr}$, less than one-third of the national MSCS increase. Although $\sim 70 \%$ of the provinces still have positive NMP, the mitigation potentials are smaller than the increase in provincial MSCS in Liaoning, Heilongjiang, Anhui, Henan, Chongqing, Sichuan, Guizhou, and Yunnan provinces (Table 4 and Fig. 2). In Shanghai, Jiangsu, Zhejiang, Fujian, Jiangxi, Hubei, Hunan, Guangdong, Guangxi, and Hainan provinces, provincial MSCS will increase after implementation of straw return, but their negative NMP values indicate that full implementation of straw return will lead to net GHG emission. The major cause of this phenomenon is the sharp increase in $\mathrm{CH}_{4}$ emission from rice paddies as a result of straw return. In the remaining 13 provinces, net mitigation potentials are larger than the increase in provincial MSCS, indicating that processes other than soil carbon sequestration are making a positive contribution to GHG mitigation.

After SOC saturation, TEGES will be $289.0 \mathrm{Tg} \mathrm{CO}_{2}-$ eqv/yr, and the national NMPS will be $-74.70 \mathrm{Tg} \mathrm{CO}_{2}^{-}$ eqv/yr (Table 5). Due to the projected increase in $\mathrm{CH}_{4}$ emission from rice fields, all of the southern provinces except Tibet have negative NMPS (Table 4 and Fig. 3). Heilongjiang, Liaoning, and Henan also have negative NMPS because paddy rice is also widely cultivated ( $>5$ $\times 10^{5} \mathrm{ha}$ ) in these provinces in northern and northeastern China. In other provinces, GHG emissions may still be reduced following SOC saturation (Table 4 and Fig. 3 ), although the total NMPS of these provinces will decrease to $13.09 \mathrm{Tg} \mathrm{CO}_{2}$-eqv/yr (Table 4). 


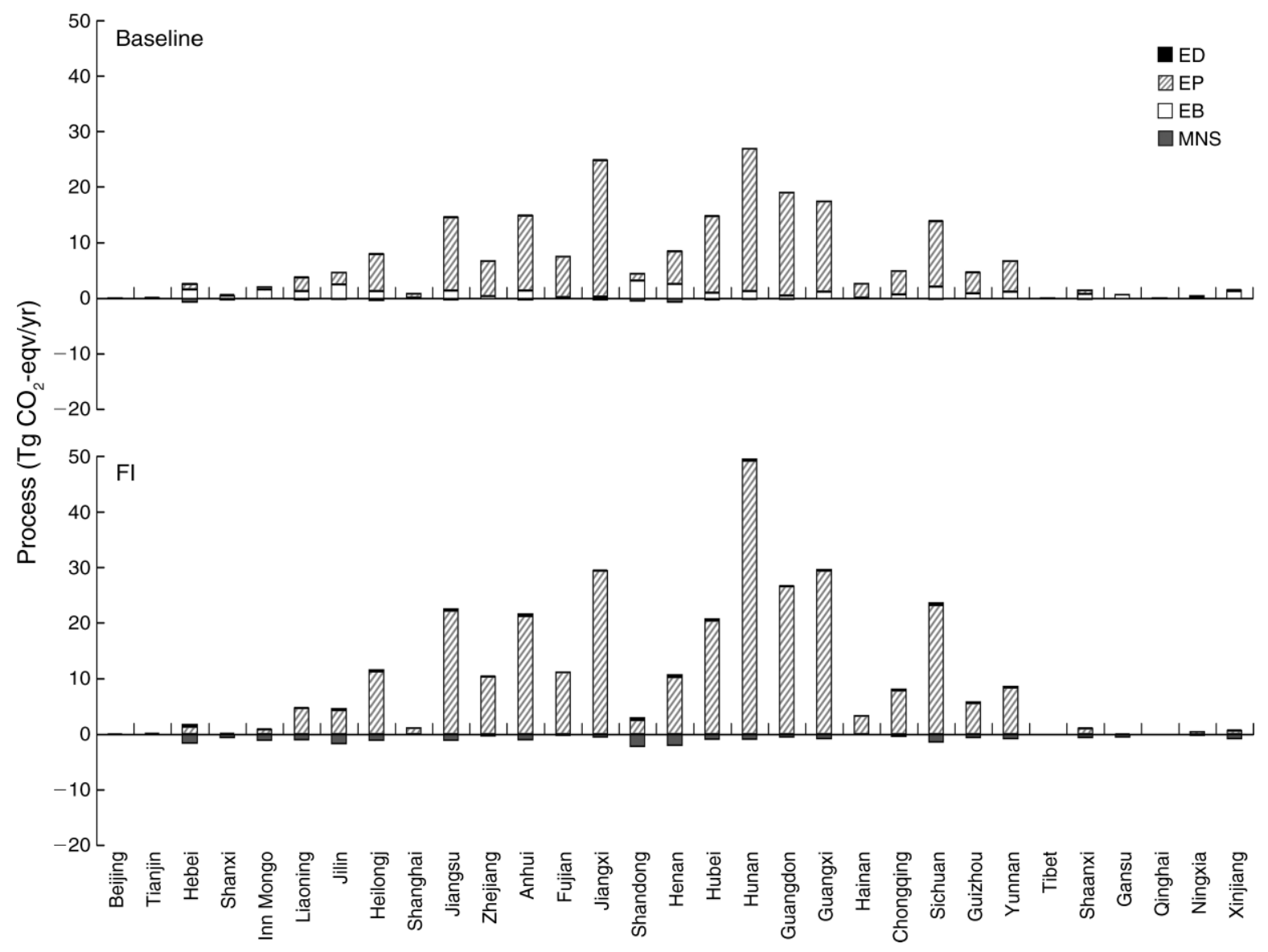

FIG. 3. Emissions, mitigation, and sequestration of each process after soil organic carbon (SOC) saturation, by Chinese province, at baseline and according to scenario FI, full implementation of straw return to the soil. See Fig. 2 for an explanation of abbreviations. EB, EP, and ED are expressed as positive values, while MNS is expressed as negative values. Data of Special Administrative Region (SAR) of Hong Kong, SAR of Macao, and Taiwan Province are not included.

\section{DisCUSSION}

Emission, sequestration, or mitigation of each process

Soil carbon sequestration.-A series of studies was previously undertaken to estimate the soil carbon sequestration potential from straw return to soil in China. Using the denitrification-decomposition (DNDC) model, Tang et al. (2006) proved that if the return ratio of non-grain aboveground crop biomass was raised from $15 \%$ to $50 \%$, the annual SOC change in the topsoil would turn from $-78.89 \mathrm{Tg} \mathrm{C} / \mathrm{yr}$ to -24.3 $\mathrm{TgC} / \mathrm{yr}$, leading to a soil carbon sequestration of 54.69 Tg C/yr. Han et al. (2008) reported that straw return would help cropland soils in China sequester $23.89 \mathrm{Tg}$ $\mathrm{C} / \mathrm{yr}$ at current levels, with an ultimate potential of 42.23 $\mathrm{Tg} \mathrm{C} / \mathrm{yr}$. Based on a review of long-term experimental data, Lu et al. (2009) estimated that the soil carbon sequestration potential from cereal straw return was 34.4 Tg C/yr. The difference between these results and the estimates obtained in this study $(11.61 \mathrm{Tg} \mathrm{C} / \mathrm{yr}$ for the baseline and $41.33 \mathrm{Tg} \mathrm{C} / \mathrm{yr}$ for the FI scenario) might stem from the method and the scenario settings.
However, all of these results confirm the importance of soil carbon sequestration through straw return.

Permanent mitigations.-Straw return can also reduce the greenhouse effect by replacing synthetic nitrogen fertilizer and avoiding non- $\mathrm{CO}_{2} \mathrm{GHG}$ emissions such as $\mathrm{CH}_{4}$ and $\mathrm{N}_{2} \mathrm{O}$ emissions from straw burning. These two mitigation effects are different from soil carbon sequestration in that they are permanent "avoidance of emission" (Smith et al. 2007).

In the SRBM, the parameters were based on the assumption that $6.408 \mathrm{Mg} \mathrm{CO}_{2}$-eqv (or $1.748 \mathrm{Mg} \mathrm{Ce}$ ) of GHG was emitted to produce each megagram of synthetic nitrogen fertilizer. This is much higher than the value of $0.8141 \mathrm{Mg} \mathrm{C}$-eqv/Mg $\mathrm{N}$ employed by West and Marland (2002). The extremely high value of GHG emission from fertilizer production results from the fertilizer manufacturing process and the energy structure of China, both of which are based on coal ( $\mathrm{Lu}$ et al. 2008), "the most destructive" energy type (Ellison 2007).

Avoiding GHG emission by not burning straw provides the greatest mitigation effect after soil carbon sequestration. This effect will be permanent after SOC 
saturation. Straw burning is still a common practice in China's countryside. Depending on the scenario settings, it was estimated that in 2000 the total global warming potential of the $\mathrm{CH}_{4}$ and $\mathrm{N}_{2} \mathrm{O}$ emissions from straw burning would be 23.93-54.56 $\mathrm{Tg} \mathrm{CO}_{2}$-eqv/yr (Duan 1995). This is very close to the estimate of $30.20 \mathrm{Tg} \mathrm{CO}_{2}^{-}$ eqv/yr obtained using the SRBM.

Methane emission from rice paddies.-Straw return can increase $\mathrm{CH}_{4}$ emission from rice paddies (Huang et al. 1998a,b, Yan et al. 2005). In this study, $\mathrm{CH}_{4}$ emission from rice paddies was $7.568 \mathrm{Tg}$ for the baseline scenario and $12.30 \mathrm{Tg}$ for the FI scenario. This increase of $4.734 \mathrm{Tg} / \mathrm{yr}$, equivalent to an increase in GWP of 118.4 $\mathrm{Tg} \mathrm{CO}_{2}$-eqv/yr, turned out to be the largest offset to the mitigation effect of straw return. As paddy rice is one of the most important crops in China, the increase in $\mathrm{CH}_{4}$ emission from rice paddies and its GWP after straw return should be viewed as an important GHG source in related studies.

Emissions from machinery use for straw return.-This effect was relatively small, accounting for $\sim 3.5 \%$ of the MSCS in both the baseline and FI scenarios. In view of the greenhouse effect, the emissions from increased use of machinery for straw return were minor compared with other sectors of emission and mitigation in the SRBM.

Direct $\mathrm{N}_{2} \mathrm{O}$ emission from soil.-Nitrous oxide $\left(\mathrm{N}_{2} \mathrm{O}\right)$ is one of three major GHGs emitted from cropland soils and may be the most important GHG emitted from Chinese cropland ( $\mathrm{Li}$ et al. 2003a). Application of synthetic nitrogen and organic amendments including straw return leads to an increase in direct $\mathrm{N}_{2} \mathrm{O}$ emission from cropland soils. According to the results of a DNDC simulation performed on a site in Hebei Province, China, the soil could sequester $3100 \mathrm{~kg} \mathrm{CO}_{2-}$ eqv $\cdot \mathrm{ha}^{-1} \cdot \mathrm{yr}^{-1}$ in SOC, but the resulting direct $\mathrm{N}_{2} \mathrm{O}$ emission increased from $13 \mathrm{~kg} \mathrm{~N} \cdot \mathrm{ha}^{-1} \cdot \mathrm{yr}^{-1}$ to $20 \mathrm{~kg}$ $\mathrm{N} \cdot \mathrm{ha}^{-1} \cdot \mathrm{yr}^{-1}$ (Li et al. 2005a). The $\mathrm{N}$ in the straw was returned to cropland and became an additional $\mathrm{N}$ input, which might be a major cause for the rise in direct $\mathrm{N}_{2} \mathrm{O}$ emission. In this study, we focused on the substitution of synthetic nitrogen fertilizer by straw return and the corresponding mitigation effect. In accordance with the scenario rules, the combined total of synthetic $\mathrm{N}$ and $\mathrm{N}$ from applied straw was maintained at a constant value. As a result, there was no significant difference in the amount of direct $\mathrm{N}_{2} \mathrm{O}$ emission according to current estimating methods (IPCC 2000, Zheng et al. 2004), and therefore there would be no influence on the net mitigation effect of straw return. Because of this, direct $\mathrm{N}_{2} \mathrm{O}$ emission was not regarded as an influential effect in the SRBM and was not considered when calculating TEGE.

\section{Net mitigation potentials}

The net mitigation potential (NMP or NMPS) indicates the net contribution to global warming mitigation incurred by changing the straw treatment

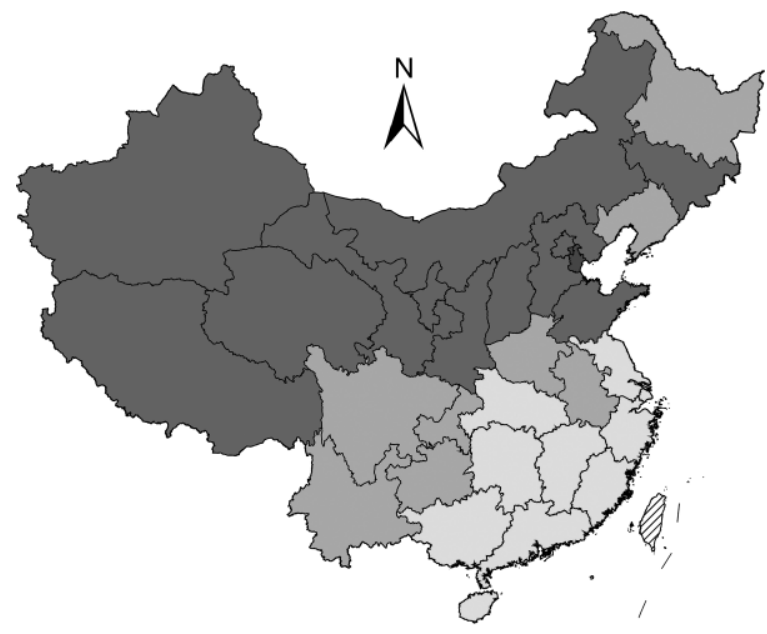

Feasible and permanent $\quad \backslash \because \ldots$

Feasible for some years but not permanent

Not feasible

IIIA Lack of data
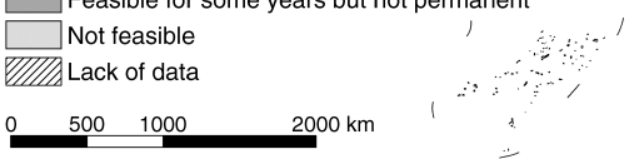

FIG. 4. Feasibility and permanence of straw return to soil as a mitigation measure.

from the baseline to the FI scenario. From the sign of the NMP or NMPS in the FI scenario, the feasibility and permanence of the mitigation of straw return may be obtained.

A positive value of NMP in the FI scenario indicates that implementation of straw return will reduce the GHG content in the atmosphere prior to SOC saturation, while a negative NMP indicates that further implementation of straw return will lead to greater overall GHG emission. As the NMP value before SOC saturation is negative, straw return cannot be regarded as a feasible mitigation measure in Shanghai, Jiangsu, Zhejiang, Fujian, Jiangxi, Hubei, Hunan, Guangdong, Guangxi, and Hainan provinces (Fig. 4). For the remaining 21 provinces in mainland China, straw return can reduce the greenhouse effect before SOC saturation, with a total net mitigation potential of $71.89 \mathrm{Tg} \mathrm{CO}_{2}$ eqv/yr (Table 4, Fig. 2), which is equal to $1.733 \%$ of the annual carbon emission from fossil fuel use in China in 2003 (1131 Tg C/yr or $4147 \mathrm{Tg} \mathrm{CO}_{2} / \mathrm{yr}$; Marland et al. 2006).

In the 21 provinces with positive NMP, Liaoning, Heilongjiang, Anhui, Henan, Chongqing, Sichuan, Guizhou, and Yunnan provinces have negative NMPS. In these eight provinces, the reduction in greenhouse effect will gradually diminish following SOC saturation (Table 5, Fig. 4). Straw return in these provinces can be a feasible mitigation measure for some years, but the mitigation benefit is not permanent.

It should be noted that negative values of NMPS do not imply that we should discontinue straw return to the soil and burn the straw in the fields after SOC 
saturation. Straw return should still be maintained in those provinces that have positive NMP but negative NMPS. Soil carbon sinks resulting from sequestration activities will continue as long as a carbon-sequestering management practice is maintained (Smith et al. 2007). Stopping straw return will cause the carbon sequestered in the soil to be emitted back into the atmosphere. For practical purposes, in order to implement a meaningful carbon sequestration policy, management changes such as returning the straw that was previously burned must be permanent (Freibauer et al. 2004). Mitigation benefits may continue for decades in these provinces before the beneficial effects are fully countered by the negative NMPS after SOC saturation. This may act as a "buy time" mitigation measure as part of a host of short- and medium-term climate mitigation measures implemented while more permanent emission reduction technologies (such as non- $\mathrm{CO}_{2}$ emitting energy sources) are developed (Smith 2004).

\section{Uncertainties}

For national or global mitigation potentials, it is very difficult to get an accurate estimate because of the large variation in climates, soil characteristics, and agricultural practices. So, attention should be paid to the uncertainties in the estimation of mitigation potentials when assessing the feasibilities and risks of promoting some sequestration and mitigation measures. In this study, the final results of the model, i.e., the net mitigation potentials, were determined by the emissions, mitigations, and sequestrations of the processes in different scenarios. As a result, uncertainties in the estimation generally come from each of the GHG emission or mitigation sectors.

In this study, soil carbon sequestration, which made the greatest contribution to GHG mitigation, was calculated simply by multiplying the soil carbon sequestration rate by the area on which straw return was implemented. So the method and data source for obtaining the soil carbon sequestration rates of straw return are very critical. The method for estimating the soil carbon sequestration rates of straw return was based on the linear relationship between the SCSR and the amount of the straw returned. The best explanation by this linear relationship was $70 \%$ and the worst was $42.9 \%$. Some uncertainties are due to the limited number of field experimental sites and data. Compared with the large cropland area, there are only a few long-term experimental data (from the field experimental sites located in 18 provinces; Appendix D) available for estimation of the soil carbon sequestration rates.

The methane emission factors of rice paddies were estimated by averaging the values given in experimental reports for each type of rice in each agricultural region based on 1 to 47 pairs of data (Table 3). The estimation did not take the basic soil condition, climate, and irrigation into account because the data of these key factors were not totally available in agricultural yearbooks or related documents. In this study, the variations of those factors were not considered. Paddy rice is planted in 30 of the 31 provinces, municipalities, and autonomous regions in the mainland of China; however, field experiments on methane emission have only been conducted in 10 provinces and municipalities, i.e., Liaoning, Beijing, Jiangsu, Zhejiang, Hubei, Hunan, Guangdong, Chongqing, Sichuan, and Yunnan (Appendix E). Although the results of the field experiments are representative to a certain extent, there may still exist some uncertainties.

\section{Comparison between scenarios}

In previous studies on the net mitigation (or sequestration) potentials, the major sources included (1) soil and underground biomass, including the organic input from roots (Lu et al. 2008), disturbance (West and Marland 2002), nitrification, and denitrification reactions producing $\mathrm{N}_{2} \mathrm{O}$ ( $\mathrm{Li}$ et al. 2005a), and environmental $\mathrm{CH}_{4}$ emission (Li et al. 2005b, 2006); and (2) external greenhouse effects related to energy consumption such as use of agricultural machinery (West et al. 2002, Chen et al. 2008), pesticides (West and Marland 2002), and synthetic fertilizer (Schlesinger 2000, Lal 2004b, Lu et al. 2008). The organic input from aboveground straw was considered secondary (West et al. 2002) or was not taken into account.

In the SRBM, it is clear that the four major processes, i.e., soil carbon sequestration, $\mathrm{CH}_{4}$ emission, non- $\mathrm{CO}_{2}$ emission from straw burning, and synthetic nitrogen fertilizer substitution, are all closely related to straw. Changes to these four processes and the net mitigation potential from implementing straw return depend on the flows of carbon and nitrogen under different treatments. From the standpoint of net emissions in a single scenario, increased non- $\mathrm{CO}_{2}$ greenhouse gas emissions may fully offset the SOC increase achieved by straw return ( $\mathrm{Li}$ et al. 2005a). However, the net mitigation potential is derived from the difference between the paired scenarios and not decided by a single scenario or treatment. If current practices such as straw burning lead to greater net emissions, straw return may still be regarded as a mitigation measure. We suggest that fully comparable scenarios should be constructed to estimate the mitigation potentials of various existing treatments for organic wastes such as straw, manure, and slurry.

In recent years, the economic, social, and environmental problems caused by straw burning in the fields and the benefits from straw return have drawn broad attention. In the "Management methods of straw comprehensive use and prohibition of straw burning" promulgated by the State Council of the People's Republic of China in 1999, straw return occupied a prominent position among projects for straw utilization. In this study, two treatments of straw, i.e., return to croplands or burning, were adopted in the scenario designs. These two are the most popular methods of disposing of the straw of the nine crop species in China. 
However, straw may also serve as fuel, forage, or industrial raw material. A recent study in Europe by Powlson et al. (2008) compared the mitigation effect of straw combustion for electric power generation with soil carbon sequestration through straw return. The methods discussed in this study should be noted even though the fate of straw combustion for power generation in China is not clear due to technical and economic barriers and the risk of soil degradation (Martinelli and Filoso 2008). In order to determine the disposition method most beneficial to mitigation, it is necessary to estimate the net emissions of each treatment. This study has taken the first step toward this goal.

\section{CONCLUSIONS}

Straw return is regarded as an important agricultural measure to mitigate the GHG in the atmosphere. However, its net contribution to GHG mitigation still has considerable uncertainties. Changing the treatment method from straw burning to straw return will alter the flow of carbon and nitrogen, resulting in different levels of GHG mitigation. Based on the carbon-nitrogen cycles and GHG mitigation and emission processes related to straw return and burning (i.e., soil carbon sequestration, mitigation of synthetic $\mathrm{N}$ fertilizer substitution, $\mathrm{CH}_{4}$ emission from rice paddies, additional fossil fuel use for straw return, and $\mathrm{CH}_{4}$ and $\mathrm{N}_{2} \mathrm{O}$ emissions from straw burning in the fields), a full $\mathrm{GHG}$ budget model (SRBM) was constructed to estimate the net mitigation potential of straw return.

For the national total, when the full budget of GHGs is considered, the change from straw burning to straw return will bring about a net mitigation potential of 34.18 $\mathrm{Tg} \mathrm{CO}_{2}$-eqv/yr before SOC saturation, which is only one-third of the mitigation effect of soil carbon sequestration. After SOC saturation, straw return will lead to more GHG emission and the net mitigation potential will be $-74.78 \mathrm{Tg} \mathrm{CO}_{2}$-eqv/yr. On a provincial scale, the net mitigation potentials of straw return also have different trends compared to soil carbon sequestration alone and varied considerably among the provinces. Before SOC saturation, straw return can mitigate greenhouse gas in 21 provinces. If straw return is implemented in these provinces, the total net mitigation potential will be $71.89 \mathrm{Tg} \mathrm{CO}_{2}$-eqv/yr. On the other hand, straw return in the remaining 10 provinces will result in greater GHG emission than straw burning and therefore cannot be regarded as a feasible mitigation measure. Besides the above-mentioned 10 provinces whose net mitigation potentials before (NMP) and after SOC saturation (NMPS) are both negative, eight more provinces in northeastern and northern China have negative NMPS, meaning that in these eight provinces straw return is only a "buy time" carbon mitigation measure and the greenhouse effect reduction will gradually diminish after SOC saturation. The major obstacle to the feasibility or permanence of straw return as a mitigation measure is the increased $\mathrm{CH}_{4}$ emission from rice paddies.

This suggests that comparable scenarios in which all the related carbon-nitrogen cycles are taken into account should be designed to estimate the net mitigation potentials stemming from different treatment and utilization methods for organic wastes such as straw, manure, and slurry. Meanwhile, spatial and temporal variations of the net mitigation potential should also be addressed.

\section{ACKNOWLEDGMENTS}

This study was supported by NSF of China (40321101), Ministry of Science and Technology, PRC (2002CB412503), and the Chinese Academy of Sciences (KZCX1-SW-01-17). We also acknowledge Yafei Yuan for constructive comments and suggestions on this paper.

\section{Literature Cited}

Cao, G., X. Zhang, Y. Wang, and F. Zheng. 2007. Estimating the quantity of air pollutant emission due to crop residues burnt in open field in China. Chinese Science Bulletin 52(15): 1826-1831. [In Chinese.]

Chen, P., X. Wang, and L. Wang, editors. 2008. Carbon budget and its sink promotion of terrestrial ecosystem in China. Science Press, Beijing, China. [In Chinese.]

Cui, X. 2007. The status quo and prospects of straw electricity generation. Pollution Control Technology 20(3):61-63. [In Chinese.]

Dai, Z., X. Deng, X. Lai, and Z. Zheng. 2000. Technique of cotton stalks returned to field and preliminary calculation of stalk nutrient quantity in Xinjiang. Acta Gossypli Sinica 12(5):264-266. [In Chinese.]

Dong, W., C. Hu, and Y. Zhang. 2005. Effect of straw on ammonia volatilization loss from urea. Journal of Hebei Agricultural Sciences 9:11-14. [In Chinese.]

Duan, Z. 1995. The dynamics and trends of $\mathrm{CH}_{4}$ and $\mathrm{N}_{2} \mathrm{O}$ emission from crop straw burning in China (1990-2020). Agro-Environmental Protection 14(3):111-116. [In Chinese.]

Editorial Board of China Agriculture Yearbook. 2005. China Agriculture Yearbook 1980-2005. Electronic Edition. China Agriculture Press, Beijing, PRC. [In Chinese.]

Ellison, K. 2007. Crisis and opportunity in China. Frontiers in Ecology and the Environment 5(8):452.

Freibauer, A., M. D. A. Rounsevell, and P. Smith. 2004. Carbon sequestration in the agricultural soils of Europe. Geoderma 122(1):1-23.

Fu, Y., F. Fan, and Y. Fu. 2007. Influence factors and resolution about the straw power generation in China. Journal of Shenyang Institute of Engineering (Natural Science) 3(3):206-210. [In Chinese.]

Gao, X., Q. Ma, C. Ma, F. Zhang, and Y. Wang. $2000 a$. Analysis on the current status of utilization of crop straw in China. Journal of Huazhong Agricultural University 21(3): 242-247. [In Chinese.]

Gao, Y., P. Zhu, D. Huang, and Z. Wang. 2000b. Long-term impact of different soil management on organic matter and total nitrogen in rice-based cropping system. Soil and Environmental Sciences 9:27-30. [In Chinese.]

$\mathrm{Gu}, \mathrm{X}$. 2007. The technical and economic analysis on stalk incineration power plant project. Renewable Energy Resources 25(4):65-67. [In Chinese.]

Han, B., X. Wang, F. Lu, X. Duan, and Z. Ouyang. 2008. Soil carbon sequestration and its potential by cropland ecosystems in China. Acta Ecologica Sinica 28:612-619. [In Chinese.] 
Han, L., Q. Yan, X. Liu, and J. Hu. 2005. Straw resources and their utilization in China. Transactions of the Chinese Society of Agricultural Engineering 18(3):87-91. [In Chinese.]

Huang, Y., R. L. Sass, and F. M. Fisher. 1998a. A semiempirical model of methane emission from flooded rice paddy soils. Global Change Biology 4:247-268.

Huang, Y., R. L. Sass, and F. M. Fisher. 1998b. Model estimates of methane emission from irrigated rice cultivation of China. Global Change Biology 4:809-821.

Huang, Y., and W. Sun. 2006. Changes in topsoil organic carbon of croplands in mainland China over the last two decades. Chinese Science Bulletin 51:1785-1803.

Hutchinson, J. J., C. A. Campbell, and R. L. Desjardins. 2007. Some perspectives on carbon sequestration in agriculture. Agricultural and Forest Meteorology 142:288-302.

IPCC [Intergovernmental Panel on Climate Change]. 1997. Revised 1996 IPCC guidelines for national greenhouse gas inventories. 〈http://www.ipcc-nggip.iges.or.jp/public/gl/invs5. html $\rangle$

IPCC [Intergovernmental Panel on Climate Change]. 2000. Good practice guidance and uncertainty management in national greenhouse gas inventories. 〈http://www.ipcc-nggip. iges.or.jp/public/gp/english/>

IPCC [Intergovernmental Panel on Climate Change]. 2007a. Climate change 2007: Working Group III Report. Mitigation of climate change. 〈http://www.ipcc.ch/ipccreports/ar4-wg3. $\mathrm{htm}\rangle$

IPCC [Intergovernmental Panel on Climate Change]. 2007b. Climate change 2007: Working Group I Report. The physical science basis. 〈http://www.ipcc.ch/ipccreports/ar4-wg1.htm〉

Lal, R. 2004a. Soil carbon sequestration impacts on global climate change and food security. Science 304:1623-1626.

Lal, R. 2004b. Carbon emission from farm operations. Environment International 30:981-990

Li, A. 2003. Organic fertilizer utility in current situation and its developing strategy in Hunan Province. Hunan Agricultural Sciences 2003(4):8-10. [In Chinese.]

Li, C., S. Frolking, and K. Butterbach-Bahl. 2005a. Carbon sequestration in arable soils is likely to increase nitrous oxide emissions, offsetting reductions in climate radiative forcing. Climatic Change 72:321-338.

Li, C., S. Frolking, X. Xiao, B. Moore III, S. Boles, J. Qiu, Y. Huang, W. Salas, and R. Sass. 2005b. Modeling impacts of farming management alternatives on $\mathrm{CO}_{2}, \mathrm{CH}_{4}$, and $\mathrm{N}_{2} \mathrm{O}$ emissions: a case study for water management of rice agriculture of China. Global Biogeochemical Cycles 19. [doi: 10.1029/2004GB002341]

Li, C., W. Salas, B. DeAngelo, and S. Rose. 2006. Assessing alternatives for mitigating net greenhouse gas emissions and increasing yields from rice production in China over the next twenty years. Journal of Environmental Quality 35:15541565.

Li, C., X. Xiao, S. Frolking, B. Moore, W. Salas, J. Qiu, Y Zhang, Y. Zhuang, X. Wang, S. Dai, J. Liu, X. Qin, B. Liao, and R. Sass. 2003a. Greenhouse gas emissions from croplands of China. Quaternary Science 23(5):493-503. [In Chinese.]

Li, C., Y. Zhuang, S. Frolking, J. Galloway, R. Harriss, B. Moore III, D. Schimel, and X. Wang. 2003b. Modeling soil organic carbon change in croplands of China. Ecological Applications 13:327-336.

Liu, H., G. Jiang, H. Zhuang, and K. Wang. 2008. Distribution, utilization structure and potential of biomass resources in rural China: with special references of crop residues. Renewable and Sustainable Energy Reviews 12:1402-1418.

Liu, X., W. Gao, and W. Zhu. 2001. Mechanism and techniques of straw returning. China Agriculture Press, Beijing, China. [In Chinese.]

Lu, F., X. Wang, B. Han, Z. Ouyang, X. Duan, and H. Zheng. 2008. Assessment on the availability of nitrogen fertilization in improving carbon sequestration potential of China's cropland soil. Chinese Journal of Applied Ecology 19(10): 2239-2250. [In Chinese.]

Lu, F., X. Wang, B. Han, Z. Ouyang, X. Duan, H. Zheng, and H. Miao. 2009. Soil carbon sequestrations by nitrogen fertilizer application, straw return and no-tillage in China's croplands. Global Change Biology 15:281-305.

Ma, Y., Z. Yu, Y. Jiang, W. Lou, and S. Tian. 2003. Effect of patterns of using corn stalks as manure on soil N. Soils 35: 62-65. [In Chinese.]

Marland, G., T. A. Boden, and R. J. Andres. 2006. Global, regional, and national $\mathrm{CO}_{2}$ emissions. In Trends: a compendium of data on global change. Carbon Dioxide Information Analysis Center, Oak Ridge National Laboratory, U.S. Department of Energy, Oak Ridge, Tennessee, USA. 〈http://cdiac.ornl.gov/ftp/trends/emissions/prc.dat

Martinelli, L. A., and S. Filoso. 2008. Expansion of sugarcane ethanol production in Brazil: environmental and social challenges. Ecological Applications 18:885-898.

MOA [Ministry of Agriculture of the People's Republic of China]/DOE [U.S. Department of Energy] Project Expert Team. 1998. Assessment of biomass resource availability in China. China Environmental Science Press, Beijing, China.

National Center for Services and Popularization of Agricultural Techniques. 1999. The organic fertilizer of China. China Agriculture Press, Beijing, China. [In Chinese.]

Niu, L., Y. Qin, J. Hao, and X. Niu. 1998. Effect of straw returning combined with nitrogen and phosphorus fertilizer application on soil fertility and crop yield in Quzhou experiment district. Soils and Fertilizers 1998(6):32-35. [In Chinese.]

Peng, C., P. Zhu, J. Gao, and S. Liu. 2004. The report on long term monitoring fertility of black earth in controlled sites. I: The transform of OM and N nutrition in black earth. Journal of Jilin Agricultural Sciences 29:29-33. [In Chinese.]

Post, W. M., R. C. Izaurralde, J. D. Jastrow, B. A. McCarl, J. E. Amonette, V. L. Bailey, P. M. Jardine, T. O. West, and J. Z. Zhou. 2004. Enhancement of carbon sequestration in US soils. BioScience 54:895-908.

Powlson, D. S., A. B. Riche, K. Coleman, M. J. Glendining, and A. P. Whitmore. 2008. Carbon sequestration in European soils through straw incorporation: limitations and alternatives. Waste Management 28:741-746.

Schlesinger, W. H. 2000. Carbon sequestration in soils: some cautions amidst optimism. Agriculture, Ecosystems and Environment 82:121-127.

Six, J., S. M. Ogle, F. J. Breidt, R. T. Conant, A. R. Mosier, and K. Paustian. 2004. The potential to mitigate global warming with no-tillage management is only realized when practised in the long term. Global Change Biology 10:155160

Smith, P. 2004. Carbon sequestration in croplands: the potential in Europe and the global context. European Journal of Agronomy 20(3):229-236.

Smith, P., K. W. Goulding, K. A. Smith, D. S. Powlson, J. U. Smith, P. D. Falloon, and K. Coleman. 2001. Enhancing the carbon sink in European agricultural soils: including trace gas fluxes in estimates of carbon mitigation potential. Nutrient Cycling in Agroecosystems 60:237-252.

Smith, P., et al. 2007. Policy and technological constraints to implementation of greenhouse gas mitigation options in agriculture. Agriculture, Ecosystems and Environment 118: $1-4,6-28$.

Smith, P., D. S. Powlson, M. J. Glendining, and J. U. Smith. 1997. Potential for carbon sequestration in European soils: preliminary estimates for five scenarios using results from long-term experiments. Global Change Biology 3:67-79.

Sun, R., B. Zhao, L. Zhu, J. Xu, and F. Zhang. 2003. Effects of long-term fertilization on soil enzyme activities and its role in 
adjusting-controlling and soil fertility. Plant Nutrition and Fertilizer Science 9:406-410. [In Chinese.]

Tang, H. J., J. J. Qiu, E. V. Ranst, and C. S. Li. 2006. Estimations of soil organic carbon storage in cropland of China based on DNDC model. Geoderma 134(1-2):200-206.

Triberti, L., A. Nastri, G. Giordani, F. Comellini, G. Baldoni, and G. Toderi. 2008. Can mineral and organic fertilization help sequestrate carbon dioxide in cropland? European Journal of Agronomy. [doi: 10.1016/j.eja.2008.01.009]

Vleeshouwers, L. M., and A. Verhagen. 2002. Carbon emission and sequestration by agricultural land use: a model study for Europe. Global Change Biology 8:519-530.

Wang, G. 1999. Analysis method on reducing emission of $\mathrm{SO}_{2}$ and $\mathrm{CO}_{2}$ by rural energy construction. Transactions of the Chinese Society of Agricultural Engineering 1999(1):169172. [In Chinese.]

Wang, X., X. Shi, and G. Song. 2005. Effects of long-term rice straw returning on the fertility and productivity of purplish paddy soil. Plant Nutrition and Fertilizer Science 11:302-307. [In Chinese.]

Weng, W., J. Yang, Q. Zhao, and L. Zhang. 2004. Current situation and developing direction of straw utilization technology in China. Integrated Utility of Resources in China 2004(7):18-21. [In Chinese.]

West, T. O., and G. Marland. 2002. A synthesis of carbon sequestration, carbon emissions and net carbon flux in agriculture: comparing tillage practices in the United States. Agriculture, Ecosystems and Environment 91:217-232.
Yan, L., Y. Song, J. He, Y. Chen, Y. Zhang, Y. Bao, and L. Guan. 2004. Effects of maize stems returning back to the field on the yield of plants and soil fertility. Chinese Journal of Soil Science 35:143-148. [In Chinese.]

Yan, X. Y., K. Yagi, H. Akiyama, and H. Akimoto. 2005. Statistical analysis of the major variables controlling methane emission from rice fields. Global Change Biology 11:11311141.

Yang, X., Q. Zheng, and B. Wang. 2003. Integrated utility of straw resource in Jilin Province (II). Rural Scientific Experiment 2003(2):6. [In Chinese.]

Zhang, D., Z. Han, J. Wang, H. Chen, and X. Zhu. 1999. Study on the technical regulation of straw directly returning of field in cinnamon soil in eastern areas of Hebei Province. Journal of Hebei Vocation-Technical Teachers College 13:1-6. [In Chinese.]

Zhang, Z. 1998. Effect of long-term wheat stalks returning on soil fertility and yield. Chinese Journal of Soil Science 29: 154-155. [In Chinese.]

Zheng, X., S. Han, Y. Huang, Y. Wang, and M. Wang. 2004. Re-quantifying the emission factors based on field measurements and estimating the direct $\mathrm{N}_{2} \mathrm{O}$ emission from Chinese croplands. Global Biogeochemical Cycles 18:GB2018.

Zhong, H., Y. Yue, and J. Fan. 2003. Characteristics of crop straw resources in China and its utilization. Resources Science 25(4):62-67. [In Chinese.]

\section{APPENDIX A}

Method for setting the area of the cropland (Ecological Archives A020-019-A1).

\section{APPENDIX B}

Method for setting energy-related parameters in the model (Ecological Archives A020-019-A2).

\section{APPENDIX C}

Method for setting the seasonal amount of straw dry matter returned to each hectare of rice paddy (Ecological Archives A020019-A3).

\section{APPENDIX D}

Database of soil organic carbon experiments in agricultural soils in China (Ecological Archives A020-019-A4).

\section{APPENDIX E}

Experimental data of $\mathrm{CH}_{4}$ emission from rice paddies in China (Ecological Archives A020-019-A5).

\section{APPENDIX F}

Experimental data of the influence of straw return to soil on $\mathrm{CH}_{4}$ emissions (Ecological Archives A020-019-A6).

\section{APPENDIX G}

Distribution of the experimental sites (Ecological Archives A020-019-A7). 